(2) Open Access Full Text Article

\title{
Increased Risk Of Type 2 Diabetes And Abnormal FPG Due To Shift Work Differs According To Gender: A Retrospective Cohort Study Among Thai Workers In Bangkok, Thailand
}

This article was published in the following Dove Press journal: Diabetes, Metabolic Syndrome and Obesity: Targets and Therapy

\author{
Nitt Hanprathet (1D) \\ Somrat Lertmaharit ${ }^{\prime}$ \\ Vitool Lohsoonthorn ${ }^{1,2}$ \\ Thanapoom Rattananupong ${ }^{\prime}$ \\ Palanee Ammaranond (iD ${ }^{3}$ \\ Wiroj Jiamjarasrangsi $\mathbb{B D}^{1,2}$ \\ 'Department of Preventive and Social \\ Medicine, Faculty of Medicine, \\ Chulalongkorn University, Bangkok \\ 10330, Thailand; ${ }^{2}$ Department of \\ Preventive and Social Medicine, King \\ Chulalongkorn Memorial Hospital, Tha \\ Red Cross Society, Bangkok 10330, \\ Thailand; ${ }^{3}$ Department of Transfusion \\ Medicine, Faculty of Allied Health \\ Sciences, Chulalongkorn University, \\ Bangkok 10330, Thailand
}

Purpose: The gender differential evidence of the association between shift work and type 2 diabetes risk remains scarce. This longitudinal study determines whether the association between shift-work exposure and type 2 diabetes risk and abnormal fasting plasma glucose (FPG) differs according to gender; the study aims to find the association between shift work and changes in physiological, behavioral, and psychosocial stress.

Patients and methods: This retrospective cohort study was conducted among 5947 workers (4647 female and 1300 male) aged $\leq 60$ years old in Bangkok, Thailand. Participants required a normal FPG level $(<100 \mathrm{mg} / \mathrm{dL})$ at baseline and at least two health check-up results from 2009 to 2016. Shift-work exposure history was assessed using a selfadministered questionnaire; FPG levels were measured annually. Cox proportional hazard models were used to assess the aforementioned association.

Results: During the follow-up period, 1470 new abnormal FPG and 154 new type 2 diabetes cases developed. Stratified analysis of male workers' data revealed an association was significant in the unadjusted model, which tended to be stronger after adjustment for demographic data and the baseline values of anthropometric and biochemical parameters. This was the case both for type 2 diabetes [Hazard Ratio (HR) $(95 \%$ Confidence Interval $(\mathrm{CI}))=2.98(1.58-5.62)]$ and abnormal FPG $[\mathrm{HR}(95 \% \mathrm{CI})=1.86(1.43-2.41)]$; this association was less obvious among women.

Conclusion: Shift work is a risk factor for type 2 diabetes and abnormal FPG; this risk is gender differential, being more pronounced in men. Preventive measures aiming at ameliorating shift work induced type 2 diabetes risk should pay more attention to men.

Keywords: shift-work exposure, diabetes, abnormal fasting plasma glucose, gender difference, behavioral stress, retrospective cohort study, Cox proportional hazard models

\section{Introduction}

Type 2 diabetes is a chronic disease with serious long-term complications, such as retinopathy, nephropathy, neuropathy, and cardiovascular disease ${ }^{1}$ it accounts for 5.0 million annual deaths worldwide. ${ }^{2,3}$ The global burden on public health from this disease is rapidly increasing. The International Diabetes Federation (IDF) reports that the global prevalence of diabetes increased from 151 million cases in $2000^{4}$ to 451 million cases in $2017,{ }^{2}$ a number estimated to increase to 693 million by $2045 .^{2}$ Almost half of these figures concern undiagnosed diabetics, who were at a particularly high risk of developing complications. ${ }^{2}$
Correspondence: Wiroj Jiamjarasrangsi Department of Preventive and Social Medicine, Faculty of Medicine,

Chulalongkorn University, Rama IV Road, Pathumwan, Bangkok 10330, Thailand

Tel +6622564000 ext. 3700

Fax +6622564292

Email wjiamja@gmail.com 
Studies undertaken in the last few decades report an association between shift work and multiple chronic diseases, one of which is type 2 diabetes. ${ }^{5-13}$ Shift work remains a common working schedule in certain sectors, including in the healthcare, utilities, food services, manufacturing, and transportation sectors. Approximately $21 \%$ of all workers in the European Union ${ }^{14,15}$ are engaged in shiftwork, as are $28.7 \%$ of workers in the United States, ${ }^{16}$ and $15-36 \%$ of workers worldwide. ${ }^{17}$

While epidemiological evidence of the association between shift work and type 2 diabetes risk is relatively sound, evidence pertaining to the gender differential of this association remains scarce and controversial. Based on the baseline data of a Brazilian Longitudinal Study of Adult Health (ELSA-Brazil) comprising 15,105 civil servants, a recent study by Silva-costa et al, ${ }^{11}$ reported that the association between night work and diabetes was stronger among women [(odds ratio (OR) (1.42 95\% confidence interval (CI) $)(1.39-1.45)]$ than men [OR $(95 \% \mathrm{CI})=1.06(1.04$ 1.08)]. In addition, a 2013 population-based cohort study by Eriksson et al, ${ }^{18}$ involved 3205 women and 2227 men in Sweden, and used patients aged $35-56$ years. All participants had normal glucose tolerance (NGT) at baseline. The study found that shift work is significantly associated with the increased risk of type 2 diabetes in women [OR ( $95 \%$ CI) 2.2 (1.0-4.7)]. However, after adjusting for confounding factors, this risk was found not to be statistically significant [OR $(95 \% \mathrm{CI})=1.9(0.8-4.4)]$. The same study found no such association - both in the unadjusted and adjusted models $[\mathrm{OR}(95 \% \mathrm{CI})=0.9(0.5-1.7)]$ and $[\mathrm{OR}(95 \% \mathrm{CI})=0.8$ (0.4-1.7), respectively — among male participants. These findings were contrary to those of the recent meta-analysis conducted by Gan et al in $2015 .{ }^{10}$ This meta-analysis included 12 studies with 28 independent reports involving 226,652 participants, and demonstrates that shift work was associated with an increased risk of type 2 diabetes; this increase was found to be significantly higher among men [OR $(95 \% \mathrm{CI})=1.37(1.20-1.56)]$ than women [OR $(95 \%$ $\mathrm{CI})=1.09(1.04-1.14)]$.

It was hypothesized that shift work may be related to increased diabetes risk because of its physiological (inflammation, blood coagulation, cardiac autonomic function, hypothalamus-pituitary-adrenal or HPA-axis, blood pressure), behavioral (sleep quality and length, cigarette smoking, nutrition, weight gain, physical inactivity), and psychosocial (work stress, work-life balance, recovery from work) consequences; these may appear differently in men than in women, resulting in a differential diabetes risk between these two groups when exposed to shift work. ${ }^{19}$ Additionally, it was reported that risk factors such as weight gain and reduced physical activity may unequally affect men and women in terms of later diabetes risk. ${ }^{20,21}$ It is therefore likely that shift-work induces weight gain and physical inactivity, and that it may result in a higher diabetes risk in men than women, though no epidemiological evidence currently exists to verify this claim.

Epidemiological data pertaining to this issue may provide an initial insight into the possible biological mechanisms of shift work and type 2 diabetes risk, and how these mechanisms are affected by gender. Therefore, further investigations on the gender differential of such association in studies using a longitudinal research design - those concerning both men and women and that have sufficient statistical power-are needed.

This study has multiple aims: (a) to determine the association between shift work and the risk of type 2 diabetes and abnormal fasting plasma glucose (FPG); (b) to examine whether such an association, if it exists, differences between men and women; and (c) to explore whether the association between shift work and changes in physiological, behavioral, and psychosocial stress among shift-worker groups differ according to gender. This study was undertaken in the context of a longitudinal research involving workers in two large organizations in Bangkok, Thailand.

\section{Materials And Methods Study Population}

This retrospective cohort study was conducted using workers of the Thai Red Cross Society (a humanitarian agency that consists of a large tertiary hospital, as well as a number of other health and humanitarian agencies within its jurisdiction) and Chulalongkorn University, Bangkok, Thailand. Working patterns varied among workers, who comprised healthcare professionals, academic personnel, manual workers, and general administration officers, among others. Both organizations have provided annual health check-ups for their workers since 2002, though this study focuses on the 2009-2016 period. In 2016, Thai Red Cross Society and Chulalongkorn University employed 7419 and 7749 workers, respectively, providing a total number of 15,168 employees. Only 10,309 (67.8\%) of these workers underwent an annual health check-up in 2016. Just 10,079 (66.5\%) individuals agreed to participate in the current study, had completed the self-administered questionnaires in 2016, and had health check-up results 
from 2009 to 2016. Of these, the 7039 workers with at least two health check-up results from the 2009-2016 period were included in the study. At baseline, 1092 workers were excluded for this study due to them having a FPG level of $(n=618)$, self-reported type 1 diabetes $(n=15)$, selfreported type 2 diabetes $(n=156)$, their use of diabetes medication $(n=125)$, and being aged $\geq 60$ years $(n=178)$. The numbers of eligible workers that could be used in the current study for each year within the 2009-2015 period (open cohort) were 3866 (65.0\%), 139 (2.3\%), 207 (3.5\%), 790 (13.3\%), 344 (5.8\%), 286 (4.8\%), and $315(5.3 \%)$, respectively. Accordingly, a total of 5947 workers (4647 women and 1300 men) without impaired fasting plasma glucose (IFG) $(\mathrm{FPG}<100 \mathrm{mg} / \mathrm{dL}, 5.6 \mathrm{mmol} / \mathrm{L}))$ or type 2 diabetes at baseline were followed-up until they had the onset of abnormal FPG or type 2 diabetes (Figure 1).

This study was granted ethical approval by the Ethical Review Board of the Faculty of Medicine at Chulalongkorn University (IRB.No. 282/59). Written informed consent was obtained from each participant after they had provided information for the study. Participant identity data were kept confidential and deleted before analysis. The databases did not hold any identifiable patient data.

\section{The Definition Of Shift Work}

History of shift-work exposure among the study participants was also assessed retrospectively through use of a questionnaire survey in 2016. This questionnaire contained a set of work-related questions on the occupation and type of respondents' previous and current jobs. The questions therein offered several possible alternatives: day only, night only, rotating two shifts (day/night, $12 \mathrm{hrs} / \mathrm{shift}$ ), and rotating three shifts (day/evening/night, $8 \mathrm{hrs} / \mathrm{shift}$ ). These work schedules were defined accordingly: (a) day workers (working hours between 06:00 and 18:00 hrs); (b) rotating two-shift workers (working hours comprising a 12 hrs/shift, a day shift between 06:00 and 18:00 hrs, and a night shift between 18:00 and 06:00 hrs); (c) rotating three-shift workers (working hours comprising a $8 \mathrm{hrs} /$ shift, a day shift between 07:30 and 16:30 hrs, an evening shift between 16:30 and 23:30 hrs, and a night shift between 23:30 and 07:30 hrs); (d) permanent night shift or night only (working hours between 18:00 and 06:00 hrs for at least $8 \mathrm{hrs} /$ night). Additional data were collected on the intensities of the day, evening, and night shiftwork (times/month), total working durations (in years), and shiftwork starting and end dates; these data were then used to retrospectively assess shift workers status at a baseline year. As a few workers only worked during nightshifts $(7.5 \%$ of men and $4.2 \%$ of women), type of job schedule was therefore redefined into three groups. Day workers were defined as including those who: (a) had never done shift work or else who rotated between two or three shifts or; (b) had completed shiftwork, though with fewer than three night shifts per month until the baseline year. Current shift workers were those who: (a) did permanent night shifts only for at least three night shifts per month or; (b) who rotated between two or three shifts with at least three night shifts per month until the baseline year. Former shift workers were those who had been shift workers in the past, but who had since stopped doing shiftwork before the baseline year.

\section{Health Outcomes}

Two health outcomes were of interest in the current study: [1] type 2 diabetes (DM) defined as including at least one out of three following components: FPG level $\geq 126 \mathrm{mg} / \mathrm{dL}$ or $7.0 \mathrm{mmol} / \mathrm{L}$; physician-diagnosed diabetes (selfreported); or use of antidiabetic medication ${ }^{22}$ and, [2] abnormal FPG was defined as having IFG (FPG level $\geq 100 \mathrm{mg} / \mathrm{dL}$ or $5.6 \mathrm{mmol} / \mathrm{L})^{22}$ plus DM.

\section{Follow-Up And Person-Years}

Concerning the study's abnormal FPG outcome, 5947 workers with normal FPG level at baseline were followed-up until they displayed the onset of abnormal FPG, turned 60, became lost to follow-up, or until the end of the follow-up period (December 2016), whichever came first. Concerning the type 2 diabetes outcome, workers were also followed-up until the onset of type 2 diabetes, they became 60 , became lost to follow-up, or until the end of the follow-up period (December 2016), whichever came first.

Person-time of follow-up for each worker was calculated (in years) and continued from the baseline annual health examination year until the outcome onset year (abnormal FPG or type 2 diabetes diagnosis), they turned 60 , became lost to follow-up, or until the end of the follow-up period. The interval between the two consecutive health examinations was one year; accordingly, the person-time for those with abnormal FPG or type 2 diabetes outcomes were calculated from the first follow-up year until the mid-point between the last health examination year, and the first health examination year per the aforementioned outcomes. 


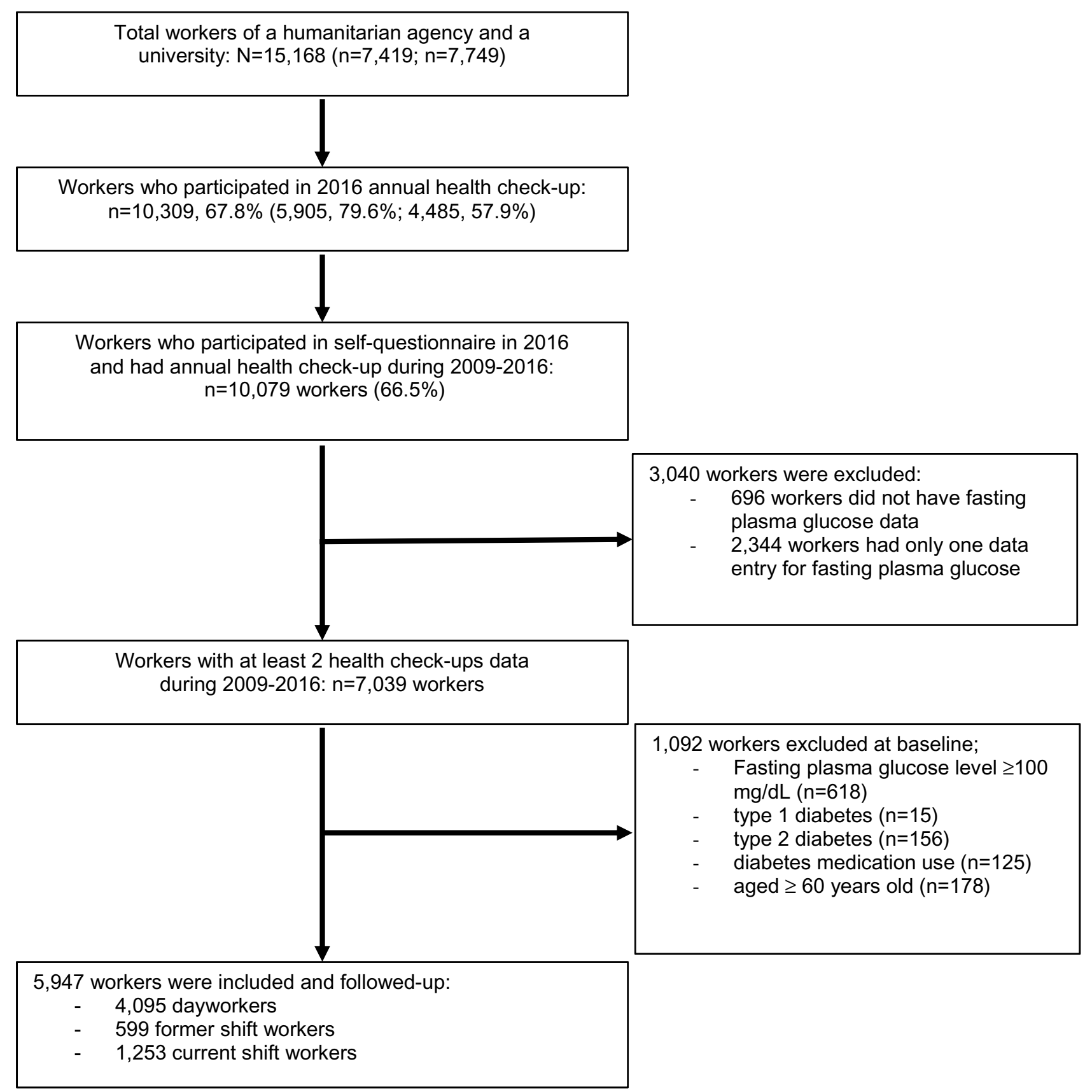

Figure I Flow chart showing the participant selection and exclusion and inclusion details.

\section{Covariate Data Collection}

The study questionnaire also collected personal characteristic data, such as data concerning the gender, age, educational level, marital status, income per month, and the personal and family health histories of workers. Baseline physiological and biochemical parameters, such as anthropometric measurements and blood samples, were collected by annual health examinations data from the 2009-2015 period. Individuals' weight, height, body mass index (BMI), waist circumference (WC), systolic blood pressure (SBP), and diastolic blood pressure (DBP) (in the sitting position) were measured by nursing staff. BMI categorizations included 'underweight' $\left(<18.5 \mathrm{~kg} / \mathrm{m}^{2}\right)$, 'normal' (18.5$\left.22.9 \mathrm{~kg} / \mathrm{m}^{2}\right)$, and "overweight/obese" $\left(\geq 23.0 \mathrm{~kg} / \mathrm{m}^{2}\right){ }^{23}$ while hypertension was defined as SBP $\geq 140$ and/or DBP $\geq 90 \mathrm{mmHg}$. Fasting plasma glucose (FPG), triglycerides (TG), high-density lipoprotein cholesterol (HDL-C), white blood cell count (WBC), were measured in a standardized 
manner at the University's biomedical laboratory. Metabolic syndrome (MetS) was defined as including four out of five following components: 1) elevated TG ( $\geq 150 \mathrm{mg} / \mathrm{dL})$; 2) a low HDL-C $(<40 \mathrm{mg} / \mathrm{dL}$ in men and $<50 \mathrm{mg} / \mathrm{dL}$ in women); 3) an elevated BP (SBP $\geq 130$ or a DBP $\geq 85 \mathrm{mmHg}$ ); 4) an elevated FPG level ( $\geq 100 \mathrm{mg} / \mathrm{dL})$; 5) a BMI $\geq 23 \mathrm{~kg} / \mathrm{m}^{2} ;{ }^{24}$ or a WC with a cut-off point for Asian populations ( $\geq 90 \mathrm{~cm}$ in men and $\geq 80 \mathrm{~cm}$ in women). ${ }^{25}$ Similar procedures were utilized in the follow-up annual health examinations. Additional data were also collected, including alcohol consumption (no/former/current), cigarette smoking (no/former/current); physical exercise, such as walking, cycling and sport (yes/no); meals eaten per day (3 times/1-2 times/>3 times), fruit and vegetable consumption of at least $0.5 \mathrm{~kg}$ per day (no or low consumption/ occasional consumption (1-3 days per week)/everyday consumption (4-7 days per week), sleep duration $(<5 \mathrm{hrs} / 5-6.9$ $\mathrm{hrs} / \geq 7 \mathrm{hrs}$ ); sleep quality, which was defined with a cut-off for Thai-PSQI ${ }^{26}$ for good sleep (score $<5$ points) and poor sleep (score $\geq 5$ points), working hours per day (6-8 hrs/ $>8-12 \mathrm{hrs} />12 \mathrm{hrs}$ ) and working hours per week ( $\leq 48 \mathrm{hrs} /$ week/>48 hrs/week).

\section{Statistical Analysis}

Descriptive statistics was used to describe the workers' characteristics. Baseline characteristics were compared among the worker groups (day, former, and current shift workers) and stratified by gender. Frequencies (as a percentage) were calculated for categorical variables and means (standard deviation: SD) or medians (interquartile ranges) for continuous variables with normal or skewed distributions, respectively. Skew data were log-transformed and ANOVA was used to assess the significant group difference, while the Chi-square test was used for categorical data. The incidence rates (IRs) and 95\% confidence intervals (CIs) of abnormal FPG and type 2 diabetes outcomes were calculated as number of new IFG+DM and DM cases divided by person-years of follow-up and reported as rate per 1000 person-years. The association between shift-work exposure with abnormal FPG or type 2 diabetes was examined by Cox proportional hazard models to estimate hazard ratios (HR), with a $95 \%$ confidence interval $(95 \% \mathrm{CI})$. Potential confounders from previous literature ${ }^{27,28}$ were managed by adding them into the existing equation for the main factor (shift-work exposure status) and outcome (abnormal FPG or diabetes) association. Proportional hazards assumption was tested using a time-dependent variable. Effect modification (interaction term) of the association between shift work and gender regarding the study outcomes was tested for all models. Following the objective of this study, the analysis was performed both overall and stratified by gender. Finally, The estimated hazard ratios (HR) were constructed as three models: an unadjusted model; Model 1, adjusted for well-established confounders, ${ }^{27,28}$ such as baseline values of age, family history of diabetes, BMI, and baseline status of hypertension; and Model 2, variables in Model 1 plus adjustment for other potential confounders such as educational level, marital status, baseline value of FPG, WBC, TG, HDL-C, and WC.

Missing data at baseline for personal characteristicssuch as educational level, and marital status $(<0.5 \%)$, as well as physiological (BMI, WC, SBP, DBP and hypertension, 2.9-4.2\%) and blood-chemistry parameters - such as white blood cell count (WBC), TG, and HDL-C (1.9-5.9\%) were managed by gender-specific mean imputation ${ }^{29}$ before multivariate hazard ratios (HR) were performed. Sensitivity analysis was performed to compare the main results between imputed and unimputed datasets.

After the gender differential in shift-work exposure and risk of abnormal FPG and diabetes had been calculated, we further examined the possible pathways that may explain this phenomenon by conducting shift-work group comparisons - separately for men and women-on those parameters relating to the physiological (incidence of hypertension, overweight/obesity, and MetS), behavioral (prevalence of alcohol consumption, cigarette smoking, physical exercise and adequate level physical activity, and frequency of fruit and vegetable consumption), and psychosocial (sleep duration and quality, daily and weekly working hours, and number of days off per week) stresses. The incidence rates of hypertension, overweight/obesity, and MetS used in these comparisons were calculated in a similar manner as those for abnormal FPG and diabetes. All statistical analyses were performed using STATA/IC version 14 (StataCorp. 2015. Stata Statistical Software: release 14, College Station, TX: StataCorp LP.)

\section{Results}

\section{Participants Characteristics}

The mean age of all workers was $40.5 \pm 7.4$ years. Concerning female participants, current shift workers used in this study were younger than both day and former shift workers; concerning male participants, the ages of current, day, and former shift workers were comparable (Table 1). The educational level of current 
Table I Comparison Of Baseline Demographics And Work-Related Data Of The Three Groups Of Workers, Stratified By Gender

\begin{tabular}{|c|c|c|c|c|c|c|c|c|c|c|c|c|}
\hline \multirow[t]{4}{*}{ Characteristics } & \multicolumn{6}{|c|}{ Female $(n=4647)$} & \multicolumn{6}{|c|}{ Male $(n=1300)$} \\
\hline & \multirow{2}{*}{\multicolumn{2}{|c|}{$\begin{array}{l}\text { Day } \\
\text { Workers } \\
(n=3049)\end{array}$}} & \multicolumn{2}{|c|}{$\begin{array}{l}\text { Former Shift } \\
\text { Workers }\end{array}$} & \multicolumn{2}{|c|}{$\begin{array}{l}\text { Current Shift } \\
\text { Workers }\end{array}$} & \multicolumn{2}{|c|}{$\begin{array}{l}\text { Day } \\
\text { Workers }\end{array}$} & \multicolumn{2}{|c|}{$\begin{array}{l}\text { Former Shift } \\
\text { Workers }\end{array}$} & \multicolumn{2}{|c|}{$\begin{array}{l}\text { Current Shift } \\
\text { Workers }\end{array}$} \\
\hline & & & \multicolumn{2}{|c|}{$(n=491)$} & \multicolumn{2}{|c|}{$(n=I \mid 07)$} & \multicolumn{2}{|c|}{$(n=1046)$} & \multicolumn{2}{|c|}{$(n=108)$} & \multicolumn{2}{|c|}{$(n=146)$} \\
\hline & $\mathbf{N}$ & $\%$ & $\mathbf{N}$ & $\%$ & $\mathbf{N}$ & $\%$ & $\mathbf{N}$ & $\%$ & $\mathbf{N}$ & $\%$ & $\mathbf{N}$ & $\%$ \\
\hline \multicolumn{13}{|l|}{ Age at baseline (years old) } \\
\hline$<35$ & 478 & 15.7 & 43 & $8.8^{\mathrm{b}}$ & 304 & $27.5^{\mathrm{c}, \mathrm{d}}$ & 115 & 11.0 & 12 & II.I & 20 & 13.7 \\
\hline $35-45$ & 1697 & 55.6 & 264 & 53.8 & 603 & 54.4 & 654 & 62.5 & 64 & 59.3 & 80 & 54.8 \\
\hline $46-59$ & 874 & 28.7 & 184 & 37.4 & 200 & 18.1 & 277 & 26.5 & 32 & 29.6 & 46 & 31.5 \\
\hline Age (years; mean $\pm S D$ ) & \multicolumn{2}{|c|}{$40.8 \pm 7.4$} & \multicolumn{2}{|c|}{$43.0 \pm 7.8^{b}$} & \multicolumn{2}{|c|}{$38.2 \pm 7.4^{\mathrm{c}, \mathrm{d}}$} & \multicolumn{2}{|c|}{$40.9 \pm 6.6$} & \multicolumn{2}{|c|}{$41.2 \pm 7.3$} & \multicolumn{2}{|c|}{$41.1 \pm 7.5$} \\
\hline \multicolumn{13}{|l|}{ Educational level ${ }^{\mathrm{a}}$} \\
\hline $6-12$ years & 721 & 23.8 & 86 & $17.6^{\mathrm{b}}$ & 422 & $38.3^{c, d}$ & 282 & 27.0 & 50 & $46.7^{\mathrm{b}}$ & 115 & $78.8^{\mathrm{c}, \mathrm{d}}$ \\
\hline$>12$ years & 2311 & 76.2 & 403 & 82.4 & 681 & 61.7 & 762 & 73.0 & 57 & 53.3 & 31 & 21.2 \\
\hline \multicolumn{13}{|l|}{ Marital status ${ }^{\mathrm{a}}$} \\
\hline Single/Divorce & 1446 & 47.6 & 212 & 43.3 & 567 & $5 I .5^{\mathrm{c,d}}$ & 341 & 32.6 & 31 & 29.0 & 47 & 32.2 \\
\hline Married & 1589 & 52.4 & 278 & 56.7 & 534 & 48.5 & 704 & 67.4 & 76 & 71.0 & 99 & 67.8 \\
\hline \multicolumn{13}{|l|}{ Income per month ${ }^{\mathrm{a}}$} \\
\hline$<20,000$ Baht & 734 & 24.2 & 19 & $18.5^{\mathrm{b}}$ & 279 & $25.3^{d}$ & 258 & 24.7 & 41 & $38.3^{\mathrm{b}}$ & 88 & $60.3^{c, d}$ \\
\hline 20,000-30,000 Baht & 1062 & 35.0 & 130 & 26.5 & 409 & 37.0 & 279 & 26.7 & 36 & 33.6 & 46 & 31.5 \\
\hline$>30,000$ Baht & $|24|$ & 40.8 & 270 & 55.0 & 417 & 37.7 & 507 & 48.6 & 30 & 28.1 & 12 & 8.2 \\
\hline \multicolumn{13}{|l|}{ Family history of Diabetes } \\
\hline No/Unknown & 1945 & 63.8 & 302 & 61.5 & 737 & 66.6 & 709 & 67.8 & 71 & 65.7 & 99 & 67.8 \\
\hline Yes & 1104 & 36.2 & 189 & 38.5 & 370 & 33.4 & 337 & 32.2 & 37 & 34.3 & 47 & 32.2 \\
\hline \multicolumn{13}{|l|}{ Occupation } \\
\hline Healthcare professional & 569 & 18.7 & 334 & $68^{\mathrm{b}}$ & 887 & $80.2^{c, d}$ & 95 & 9.1 & 23 & $21.3^{\mathrm{b}}$ & 54 & $37.0^{c, d}$ \\
\hline Academic personnel & 412 & 13.5 & 15 & 3.1 & 9 & 0.8 & 316 & 30.2 & 8 & 7.4 & I & 0.7 \\
\hline $\begin{array}{l}\text { Security guards, drivers } \\
\text { and maintenance } \\
\text { technicians }\end{array}$ & 5 & 0.2 & 0 & 0.0 & 7 & 0.6 & 126 & 12.0 & 22 & 20.4 & 47 & 32.2 \\
\hline Fulfilled other roles & 2063 & 67.6 & 142 & 28.9 & 204 & 18.4 & 509 & 48.7 & 55 & 50.9 & 44 & 30.1 \\
\hline \multicolumn{13}{|l|}{ Type of shift work } \\
\hline Fixed shift work & & & & & 47 & 4.2 & & & & & 11 & 7.5 \\
\hline Rotated shift work & & & & & 1060 & 95.8 & & & & & 135 & 92.5 \\
\hline Work duration (years) & & & & & & & & & & & & \\
\hline Mean \pm SD & $19.9 \pm$ & & 23.3 & & $21.5 \pm$ & & 18.8 & 8.9 & 18. & & 21.3 & \\
\hline
\end{tabular}


Table I (Continued).

\begin{tabular}{|c|c|c|c|c|c|c|c|c|c|c|c|c|}
\hline \multirow[t]{4}{*}{ Characteristics } & \multicolumn{6}{|c|}{ Female $(n=4647)$} & \multicolumn{6}{|c|}{ Male $(n=1300)$} \\
\hline & \multirow{2}{*}{\multicolumn{2}{|c|}{$\begin{array}{l}\begin{array}{l}\text { Day } \\
\text { Workers }\end{array} \\
(n=3049)\end{array}$}} & \multirow{2}{*}{\multicolumn{2}{|c|}{$\begin{array}{l}\begin{array}{l}\text { Former Shift } \\
\text { Workers }\end{array} \\
(n=491)\end{array}$}} & \multirow{2}{*}{\multicolumn{2}{|c|}{$\begin{array}{l}\text { Current Shift } \\
\text { Workers } \\
(n=\mid 107)\end{array}$}} & \multirow{2}{*}{\multicolumn{2}{|c|}{$\begin{array}{l}\begin{array}{l}\text { Day } \\
\text { Workers }\end{array} \\
(n=1046)\end{array}$}} & \multirow{2}{*}{\multicolumn{2}{|c|}{$\begin{array}{l}\text { Former Shift } \\
\text { Workers } \\
(n=108)\end{array}$}} & \multirow{2}{*}{\multicolumn{2}{|c|}{$\begin{array}{l}\text { Current Shift } \\
\text { Workers }\end{array}$}} \\
\hline & & & & & & & & & & & & \\
\hline & $\mathbf{N}$ & $\%$ & $\mathbf{N}$ & $\%$ & $\mathbf{N}$ & $\%$ & $\mathbf{N}$ & $\%$ & $\mathbf{N}$ & $\%$ & $\mathbf{N}$ & $\%$ \\
\hline \multicolumn{13}{|c|}{ Shift work duration (years) } \\
\hline Mean \pm SD & & & \multicolumn{2}{|c|}{$10.8 \pm 8.3$} & \multicolumn{2}{|c|}{$20.4 \pm 8.1$} & & & \multicolumn{2}{|c|}{$7.7 \pm 6.7$} & \multicolumn{2}{|c|}{$20.6 \pm 8.3$} \\
\hline \multicolumn{13}{|c|}{ Shift work intensity (days/month) } \\
\hline Median \pm IQR & & & & & \multicolumn{2}{|c|}{$8 \pm 4$} & & & & & \multicolumn{2}{|c|}{$9 \pm 5$} \\
\hline \multicolumn{13}{|c|}{ Quitting shift work (years) } \\
\hline Mean \pm SD & & & \multicolumn{2}{|c|}{$9.5 \pm 7.5$} & & & & & \multicolumn{2}{|c|}{$10.8 \pm 7.2$} & & \\
\hline
\end{tabular}

Notes: ${ }^{a}$ Missing data $<0.5 \%{ }^{\mathrm{b}}$ significant difference between former shift workers and day workers at $\mathrm{p}$-value $<0.05$; ${ }^{\mathrm{c}}$ significant difference between current shift workers and day workers at $p$-value $<0.05$; ${ }^{d}$ significant difference between current shift workers and former shift workers at $p$-value $<0.05$.

Abbreviations: N, Number; SD, Standard Deviation; IQR, Interquartile range.

shift workers was higher than that of the other two groups, as indicated by their higher proportion of those having 6-12 years of education. The proportion of female workers who were not in a partnership (single or divorced) was higher among current shift workers than the other two groups, while the reverse was true regarding male workers. Proportions pertaining to a family history of diabetes did not differ among the three groups. A majority of female current shift workers worked as healthcare professionals $(80.2 \%)$, while the majority of male current shift workers worked as healthcare professionals $(37.0 \%)$ and security guards, drivers, and maintenance technicians $(32.2 \%)$. The mean durations of current shift workers were $20.4 \pm 8.1$ years for women, and $20.6 \pm 8.3$ years for men. Concerning the group of former shift workers, the mean duration spent before workers quit their shift work was $10.8 \pm 8.3$ years for women and 7.7 \pm 6.7 years for men (Table 1).

Concerning baseline physiological and biochemical parameters for both male and female current shift workers, WBC counts were significantly higher than those of the other two groups, while FPG levels were significantly lower than those of the other two groups. Most of the parameters concerning male current shift workers werelower than those of the other two groups; however, did not significantly differ among the three groups (Table 2).

\section{Association Between Shift-Work Exposure With The Occurrence Of Abnormal FPG And Type 2 Diabetes}

Throughout 32,534 person-years (min 0.5, mean 5.4, max 7 years) of follow-up for type 2 diabetes, 154 new type 2 diabetes cases had developed. Overall, 1470 new abnormal FPG cases had developed throughout 28,155.5 person-years (min 0.5 , mean 4.7, max 7 years) of follow-up. The overall incidence rates of abnormal FPG and type 2 diabetes did not differ significantly among the three worker groups. However, analysis according to gender revealed that, for male workers, incidence rates (IR) of both outcomes were significantly higher for current shift workers (IR=116.10 per 1000 person-years for abnormal FPG and 17.42 per 1000 personyears for DM) than they were for the other two groups [IR of abnormal $\mathrm{FPG}=79.85$ and 55.50 per 1000 person-years for day and former shift workers, respectively and IR of $\mathrm{DM}=6.37$ and 5.28 per 1000 person-years, respectively]. Incidence rates among female workers did not differ significantly among the three shift-worker groups (Tables 3 and 4).

Association between shift-work exposure and health outcomes was further analyzed using the Cox proportional hazard model, wherein day workers were treated as the reference group. The unadjusted results showed that, overall, the current shift workers group was not significantly associated with increased type 2 diabetes risk HR [95\% CI $)=1.33$ (0.94-1.89)] and abnormal FPG outcomes [0.96 (0.85-1.09)] 
Table 2 Comparison Of Baseline Physiological And Biochemical Of The Three Groups Of Workers, Stratified By Gender

\begin{tabular}{|c|c|c|c|c|c|c|}
\hline \multirow{4}{*}{$\begin{array}{l}\text { Parameter at } \\
\text { Baseline }\end{array}$} & \multicolumn{3}{|c|}{ Female $(n=4647)$} & \multicolumn{3}{|l|}{ Male $(n=\mid 300)$} \\
\hline & $\begin{array}{l}\text { Day } \\
\text { Workers }\end{array}$ & $\begin{array}{l}\text { Former Shift } \\
\text { Workers }\end{array}$ & $\begin{array}{l}\text { Current Shift } \\
\text { Workers }\end{array}$ & $\begin{array}{l}\text { Day } \\
\text { Workers }\end{array}$ & $\begin{array}{l}\text { Former Shift } \\
\text { Workers }\end{array}$ & $\begin{array}{l}\text { Current Shift } \\
\text { Workers }\end{array}$ \\
\hline & $(n=3049)$ & $(n=491)$ & $(n=1107)$ & $(n=1046)$ & $(n=108)$ & $(n=\mid 46)$ \\
\hline & (mean \pm SD) & $($ mean \pm SD) & $($ mean \pm SD) & (mean \pm SD) & $($ mean \pm SD) & $($ mean \pm SD) \\
\hline FPG (mg/dL) & $85.7 \pm 6.5$ & $85.8 \pm 6.2$ & $84.8 \pm 6.4^{\mathrm{c}, \mathrm{d}}$ & $88.5 \pm 6.3$ & $88.1 \pm 5.9$ & $86.7 \pm 6.4^{c}$ \\
\hline BMI $\left(\mathrm{kg} / \mathrm{m}^{2}\right)^{\mathrm{a}}$ & $23.3 \pm 4.1$ & $22.6 \pm 3.3^{b}$ & $22.9 \pm 3.8^{c}$ & $24.4 \pm 3.4$ & $24.6 \pm 3.8$ & $24.4 \pm 3.7$ \\
\hline $\mathrm{WC}(\mathrm{cm})^{\mathrm{a}}$ & $74.5 \pm 9.5$ & $73.2 \pm 8.0^{\mathrm{b}}$ & $73.5 \pm 8.7^{c}$ & $84.5 \pm 8.6$ & $84.1 \pm 9.7$ & $83.1 \pm 9.8$ \\
\hline $\mathrm{SBP}(\mathrm{mmHg})^{\mathrm{a}}$ & $116.1 \pm 13.2$ & $114.3 \pm 13.7^{b}$ & $112.4 \pm 12.3^{\mathrm{c}, \mathrm{d}}$ & $124.53 \pm 13.5$ & $125.8 \pm 14.4$ & $122.9 \pm 12.7$ \\
\hline $\mathrm{DBP}(\mathrm{mmHg})^{\mathrm{a}}$ & $74.5 \pm 9.5$ & $73.3 \pm 10.0^{\mathrm{b}}$ & $72.4 \pm 9.1^{c}$ & $79.6 \pm 9.8$ & $79.5 \pm 9.6$ & $78.6 \pm 8.8$ \\
\hline Hypertension (\%) ${ }^{a}$ & 13.6 & 13.9 & $8.4^{c, d}$ & 29.1 & 26.2 & 22.5 \\
\hline WBC $\left(10^{3} \text { cells } / \mu \mathrm{L}\right)^{\mathrm{a}}$ & $6.5 \pm 1.6$ & $6.3 \pm 1.6^{b}$ & $6.8 \pm 1.7^{\mathrm{c}, \mathrm{d}}$ & $6.7 \pm 1.7$ & $6.6 \pm 1.5$ & $7.1 \pm 1.6^{c}$ \\
\hline TG $(\mathrm{mg} / \mathrm{dL})^{\mathrm{a}, \mathrm{f}}$ & $80 \pm 50$ & $78 \pm 47$ & $74 \pm 49.5^{c}$ & $113 \pm 86$ & $107 \pm 71$ & $110 \pm 69$ \\
\hline HDL-C (mg/dL $)^{\mathrm{aa}, \mathrm{f}}$ & $61 \pm 20$ & $62 \pm 19$ & $61 \pm 18$ & $49 \pm 16$ & $51 \pm 15$ & $47 \pm 15$ \\
\hline
\end{tabular}

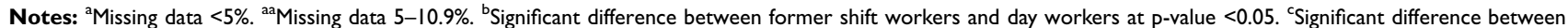
current shift workers and day workers at $\mathrm{p}$-value $<0.05$. ${ }^{\mathrm{d}}$ Significant difference between current shift workers and former shift workers at $\mathrm{p}$-value $<0.05$. ${ }^{\mathrm{f}} \mathrm{Median} \pm \mathrm{IQR}$ was shown instead of Mean \pm SD.

Abbreviations: FPG, fasting plasma glucose; BMI, body mass index; WC, waist circumference; SBP, systolic blood pressure; DBP, diastolic blood pressure; TG, triglycerides; HDL-C, high-density lipoprotein cholesterol; WBC, white blood cell count; SD, Standard Deviation; IQR, Interquartile range.

(Tables 3 and 4). After adjustment for potential confounders, the association between the current shift worker group with increased health risk was found to be both stronger and significant for both type 2 diabetes [HR $(95 \% \mathrm{CI})=1.82$ (1.27-2.60) and 1.85 (1.27-2.69) for Models 1 and 2, respectively], as well as abnormal FPG outcomes [HR (95\% CI) $=1.20(1.06-1.36)$ and $1.28(1.13-1.46)$, respectively].

Stratified analysis by gender showed that the association between current shift workers and abnormal FPG and type 2 diabetes risks were more pronounced among men but less obvious among women $(p$-interaction $<0.05$ for all model of abnormal FPG and $p$-interaction $>0.05$ for all model of type 2 diabetes). For men, such associations were only significant for the unadjusted model [HR (95\% CI) $=2.66(1.45-4.87$ and $1.44(1.12-1.85)$ for type 2 diabetes and abnormal FPG, respectively] and tended to be stronger for the adjusted models for both type 2 diabetes [HR (95\% $\mathrm{CI})=2.77(1.51-5.08)$ and $2.98(1.58-5.62)$ for Model 1 and 2, respectively] and abnormal FPG outcomes [HR $(95 \% \mathrm{CI})=1.46(1.14-1.88)$ and $1.86(1.43-2.41)$, respectively]. These associations were found to be not statistically significant for all models regarding both type 2 diabetes and abnormal FPG outcomes among women.

Overall and gender-specific analysis revealed that former shift workers were not significantly associated with increased abnormal FPG and type 2 diabetes risk when compared with day workers (Tables 3 and 4). Finally, the sensitivity analysis revealed that the magnitude of the association between shift work and abnormal FPG and type 2 diabetes did not materially alter, and that it still associated with the increased risk of type 2 diabetes and abnormal FPG (Tables 3 and 4).

\section{Distribution Of Physiological, Behavioral, And Psychosocial Stress Among Shift-Worker Groups}

Further analysis was undertaken to examine a possible pathway explaining the gender differential in shift workdiabetes risk, as described above. Accordingly, we targeted those parameters with a gender discrepancy regarding the differences between current shift and day workers. It was found that, among male workers, the incidence rates of hypertension ( 27.9 versus $18.4, \mathrm{p}=0.024)$, and MetS (29.6 versus $19.4, \mathrm{p}=0.018$ ) were significantly higher for current shift than day workers, and that the prevalence rate of physical exercise (50.0 versus $66.2, \mathrm{p}<0.001)$ was significantly lower for current shift than day workers; these findings were not the case for female workers (Table 5). Patterns of shift-work group differences for the remaining parameters between males and female workers were not dissimilar.

\section{Discussion}

This study demonstrated that current shift work is associated with increased risk of abnormal FPG or type 2 
Table 3 Hazard Ratios Of Association Between Shift Work And Abnormal FPG For The Imputed And Unimputed Datasets, Stratified By Gender

\begin{tabular}{|c|c|c|c|c|c|c|c|c|c|c|}
\hline \multirow[t]{3}{*}{ Shift Work Status } & \multirow[t]{3}{*}{ Case/N } & \multirow[t]{3}{*}{ PYs } & \multirow[t]{3}{*}{ IRs/ I000 PYs } & \multirow[t]{3}{*}{$95 \% \mathrm{Cl}$} & \multicolumn{6}{|c|}{ Abnormal FPG vs Normal } \\
\hline & & & & & \multicolumn{2}{|c|}{ Unadjusted } & \multicolumn{2}{|c|}{$\begin{array}{l}\text { Adjusted } \\
\text { Model I }\end{array}$} & \multicolumn{2}{|c|}{$\begin{array}{l}\text { Adjusted } \\
\text { Model } 2\end{array}$} \\
\hline & & & & & HR & $95 \% \mathrm{Cl}$ & HR & $95 \% \mathrm{Cl}$ & HR & $95 \% \mathrm{Cl}$ \\
\hline \multicolumn{11}{|l|}{ IMPUTED DATASET } \\
\hline Overall & | 470/5947 & $28,155.5$ & 52.21 & $49.57-54.95$ & & & & & & \\
\hline Day workers & $994 / 4095$ & 18,605 & 53.43 & $50.16-56.85$ & 1.00 & & 1.00 & & 1.00 & \\
\hline Former shift workers & $|4| / 599$ & 2948.5 & 47.82 & $40.25-56.40$ & 0.90 & $0.76-1.08$ & 0.93 & $0.78-1.12$ & 0.97 & $0.81-1.16$ \\
\hline Current shift workers & $335 / 1253$ & 6602 & 50.74 & $45.45-56.48$ & 0.96 & $0.85-1.09$ & 1.20 & $1.06-1.36$ & 1.28 & $1.13-1.46$ \\
\hline Female & $1015 / 4647$ & $22,592.5$ & 44.93 & $42.22-47.73$ & & & & & & \\
\hline Day workers & $641 / 3049$ & $14 \mid 84$ & 45.19 & $41.76-48.83$ & 1.00 & & 1.00 & & 1.00 & \\
\hline Former shift workers & || $3 / 49 \mid$ & 2444 & 46.24 & $38.10-55.59$ & 1.03 & $0.84-1.26$ & 1.03 & $0.84-1.26$ & 1.06 & $0.86-1.29$ \\
\hline Current shift workers & $261 / 1107$ & 5964.5 & 43.76 & $38.61-49.40$ & 0.98 & $0.84-1.13$ & 1.14 & $0.98-1.32$ & 1.17 & $1.01-1.36$ \\
\hline Male & $455 / 1300$ & 5563 & 81.79 & $74.45-89.66$ & & & & & & \\
\hline Day workers & $353 / 1046$ & 4421 & 79.85 & $71.73-88.63$ & 1.00 & & 1.00 & & 1.00 & \\
\hline Former shift workers & $28 / 108$ & 504.5 & 55.50 & $36.88-80.21$ & 0.70 & $0.48-1.03$ & 0.68 & $0.47-1.00$ & 0.72 & $0.49-1.06$ \\
\hline \multirow[t]{2}{*}{ Current shift workers } & $74 / 146$ & 637.5 & 116.10 & $91.15-145.73$ & 1.44 & $1.12-1.85$ & 1.46 & $1.14-1.88$ & 1.86 & $|.43-2.4|$ \\
\hline & & & \multicolumn{2}{|l|}{ p-interaction } & \multicolumn{2}{|c|}{0.0033} & \multicolumn{2}{|c|}{0.0271} & \multicolumn{2}{|c|}{0.0008} \\
\hline \multicolumn{11}{|c|}{ UNIMPUTED DATASET } \\
\hline Overall & $1470 / 5947$ & $28,155.5$ & 52.21 & $49.57-54.95$ & & & & & & \\
\hline Day workers & $994 / 4095$ & 18,605 & 53.43 & $50.16-56.85$ & 1.00 & & 1.00 & & 1.00 & \\
\hline Former shift workers & $14 \mid / 599$ & 2948.5 & 47.82 & $40.25-56.40$ & 0.90 & $0.76-1.08$ & 0.90 & $0.75-1.00$ & 0.95 & $0.79-1.15$ \\
\hline Current shift workers & $335 / 1253$ & 6602 & 50.74 & $45.45-56.48$ & 0.96 & $0.85-1.09$ & 1.21 & $1.06-1.37$ & 1.34 & $1.16-1.54$ \\
\hline Female & $1015 / 4647$ & $22,592.5$ & 44.93 & $42.22-47.73$ & & & & & & \\
\hline Day workers & $641 / 3049$ & $14 \mid 84$ & 45.19 & $41.76-48.83$ & 1.00 & & 1.00 & & 1.00 & \\
\hline Former shift workers & $|13 / 49|$ & 2444 & 46.24 & $38.10-55.59$ & 1.03 & $0.84-1.26$ & 0.99 & $0.80-1.23$ & 1.04 & $0.84-1.29$ \\
\hline Current shift workers & $261 / 1107$ & 5964.5 & 43.76 & $38.61-49.40$ & 0.98 & $0.84-1.13$ & 1.15 & $0.99-1.34$ & 1.23 & $1.06-1.44$ \\
\hline Male & $455 / 1300$ & 5563 & 81.79 & $74.45-89.66$ & & & & & & \\
\hline Day workers & $353 / 1046$ & 4421 & 79.85 & $71.73-88.63$ & 1.00 & & 1.00 & & 1.00 & \\
\hline Former shift workers & $28 / 108$ & 504.5 & 55.50 & $36.88-80.21$ & 0.70 & $0.48-1.03$ & 0.67 & $0.45-1.00$ & 0.70 & $0.46-1.06$ \\
\hline \multirow[t]{2}{*}{ Current shift workers } & $74 / 146$ & 637.5 & 116.10 & $91.15-145.73$ & 1.44 & $1.12-1.85$ & 1.44 & $1.11-1.87$ & 1.84 & $|.40-2.4|$ \\
\hline & & & \multicolumn{2}{|l|}{ p-interaction } & \multicolumn{2}{|c|}{0.0033} & \multicolumn{2}{|c|}{0.0529} & \multicolumn{2}{|c|}{0.0049} \\
\hline
\end{tabular}

Notes: Model I, Adjusted for age at baseline (years), family history of DM (no/yes), BMI at baseline $\left(\mathrm{kg} / \mathrm{m}^{2}\right)$, hypertension at baseline (yes; SBP $\geq \mathrm{I} 40 \mathrm{mmHg}$ and/or DBP

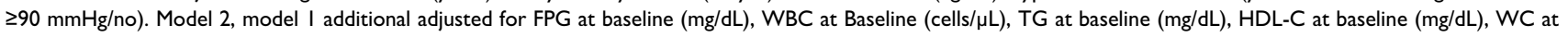
baseline $(\mathrm{cm})$, marital status (single or divorce/married), education level $(\leq 12$ years $/>12$ years).

Abbreviations: N, Number; PYs, person-years; IR, incidence rates; $95 \% \mathrm{Cl}, 95 \%$ confidence intervals; HR, hazard ratio.

diabetes. Stratified analysis by gender revealed that the association between current shift workers and abnormal FPG and type 2 diabetes risks was more pronounced among men, but less obvious among women. These findings confirm the association between current shift work and risk of abnormal FPG and type 2 diabetes, indicating that such an association is stronger in men than in women. In addition, we also provide evidence that this gender discrepancy may be mediated via the differential effect shift work has regarding the behavioral (physical exercise) and physiological (incidence of hypertension and MetS) consequences for both genders.

The results of this study are consistent with those of the recent meta-analysis conducted by Gan et al. ${ }^{10}$ However, the magnitudes of association and gender disparity were much more pronounced in the current study: [OR $(95 \%$ 
Table 4 Hazard Ratios Of Association Between Current Shift Workers And Type 2 Diabetes For The Imputed And Unimputed Datasets, Stratified By Gender

\begin{tabular}{|c|c|c|c|c|c|c|c|c|c|c|}
\hline \multirow[t]{3}{*}{ Shift-work status } & \multirow[t]{3}{*}{ Case/N } & \multirow[t]{3}{*}{ PYs } & \multirow[t]{3}{*}{ IRs/ I000 PYs } & \multirow[t]{3}{*}{$95 \% \mathrm{Cl}$} & \multicolumn{6}{|c|}{ Type 2 Diabetes Vs Normal } \\
\hline & & & & & \multicolumn{2}{|c|}{ Unadjusted } & \multicolumn{2}{|c|}{$\begin{array}{l}\text { Adjusted Model } \\
\text { I }\end{array}$} & \multicolumn{2}{|c|}{$\begin{array}{l}\text { Adjusted Model } \\
2\end{array}$} \\
\hline & & & & & HR & $95 \% \mathrm{Cl}$ & HR & $95 \% \mathrm{Cl}$ & HR & $95 \% \mathrm{Cl}$ \\
\hline \multicolumn{11}{|l|}{ IMPUTED DATASET } \\
\hline Overall & $154 / 5947$ & 32,534 & 4.73 & $4.02-5.54$ & & & & & & \\
\hline Day workers & $97 / 4095$ & 21,642 & 4.48 & $3.63-5.47$ & 1.00 & & 1.00 & & 1.00 & \\
\hline Former shift workers & $10 / 599$ & 3289 & 3.04 & $1.46-5.59$ & 0.67 & $0.35-1.29$ & 0.82 & $0.42-1.57$ & 0.72 & $0.37-1.40$ \\
\hline Current shift workers & $47 / 1253$ & 7603 & 6.18 & $4.54-8.22$ & 1.33 & $0.94-1.89$ & 1.82 & $1.27-2.60$ & 1.85 & $1.27-2.69$ \\
\hline Female & $101 / 4647$ & 25,611 & 3.94 & $3.21-4.79$ & & & & & & \\
\hline Day workers & $62 / 3049$ & $16, \mid 48.5$ & 3.84 & $2.94-4.92$ & 1.00 & & 1.00 & & 1.00 & \\
\hline Former shift workers & $7 / 491$ & 2720.5 & 2.57 & $1.03-5.30$ & 0.66 & $0.30-1.45$ & 0.81 & $0.37-1.78$ & 0.59 & $0.26-1.36$ \\
\hline Current shift workers & $32 / 1107$ & 6742 & 4.75 & $3.25-6.70$ & 1.20 & $0.78-1.83$ & 1.50 & $0.97-2.33$ & 1.52 & $0.98-2.36$ \\
\hline Male & $53 / 1300$ & 6923 & 7.66 & $5.73-10.01$ & & & & & & \\
\hline Day workers & $35 / 1046$ & 5493.5 & 6.37 & $4.44-8.86$ & 1.00 & & 1.00 & & 1.00 & \\
\hline Former shift workers & $3 / 108$ & 568.5 & 5.28 & $1.09-15.42$ & 0.83 & $0.25-2.69$ & 0.80 & $0.25-2.61$ & 1.02 & $0.31-3.34$ \\
\hline \multirow[t]{2}{*}{ Current shift workers } & $15 / 146$ & 861 & 17.42 & $9.75-28.73$ & 2.66 & $1.45-4.87$ & 2.77 & $\mathrm{I} .5 \mathrm{I}-5.08$ & 2.98 & $1.58-5.62$ \\
\hline & & & \multicolumn{2}{|l|}{ p-interaction } & \multicolumn{2}{|c|}{0.1067} & \multicolumn{2}{|c|}{0.2666} & \multicolumn{2}{|c|}{0.1960} \\
\hline \multicolumn{11}{|c|}{ UNIMPUTED DATASET } \\
\hline Overall & I54/5947 & 32,534 & 4.73 & $4.02-5.54$ & & & & & & \\
\hline Day workers & $97 / 4095$ & 21,642 & 4.48 & $3.63-5.47$ & 1.00 & & 1.00 & & 1.00 & \\
\hline Former shift workers & $10 / 599$ & 3289 & 3.04 & $1.46-5.59$ & 0.67 & $0.35-1.29$ & 0.79 & $0.40-1.58$ & 0.72 & $0.35-1.45$ \\
\hline Current shift workers & $47 / 1253$ & 7603 & 6.18 & $4.54-8.22$ & 1.33 & $0.94-1.89$ & 1.91 & $1.33-2.75$ & 2.05 & $1.40-3.02$ \\
\hline Female & $101 / 4647$ & 25,611 & 3.94 & $3.21-4.79$ & & & & & & \\
\hline Day workers & $62 / 3049$ & $16, \mid 48.5$ & 3.84 & $2.94-4.92$ & 1.00 & & 1.00 & & 1.00 & \\
\hline Former shift workers & $7 / 491$ & 2720.5 & 2.57 & $1.03-5.30$ & 0.66 & $0.30-1.45$ & 0.75 & $0.32-1.76$ & 0.57 & $0.24-1.37$ \\
\hline Current shift workers & $32 / 1107$ & 6742 & 4.75 & $3.25-6.70$ & 1.20 & $0.78-1.83$ & 1.58 & $1.01-2.45$ & 1.68 & $1.07-2.63$ \\
\hline Male & $53 / 1300$ & 6923 & 7.66 & $5.73-10.01$ & & & & & & \\
\hline Day workers & $35 / 1046$ & 5493.5 & 6.37 & $4.44-8.86$ & 1.00 & & 1.00 & & 1.00 & \\
\hline Former shift workers & $3 / 108$ & 568.5 & 5.28 & $1.09-15.42$ & 0.83 & $0.25-2.69$ & 0.85 & $0.26-2.77$ & 1.13 & $0.34-3.73$ \\
\hline \multirow[t]{2}{*}{ Current shift workers } & $15 / 146$ & 861 & 17.42 & $9.75-28.73$ & 2.66 & $1.45-4.87$ & 2.93 & $|.59-5.4|$ & 3.32 & $1.73-6.35$ \\
\hline & & & \multicolumn{2}{|l|}{ p-interaction } & \multicolumn{2}{|c|}{0.1067} & \multicolumn{2}{|c|}{0.2691} & \multicolumn{2}{|c|}{0.1845} \\
\hline
\end{tabular}

Notes: Model I, Adjusted for age at baseline (years), family history of DM (no/yes), BMI at baseline $\left(\mathrm{kg} / \mathrm{m}^{2}\right)$, hypertension at baseline (yes; SBP $\geq \mathrm{I} 40 \mathrm{mmHg}$ and/or DBP

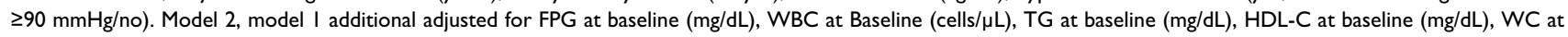
baseline $(\mathrm{cm})$, marital status (single or divorce/married), education level $(\leq 12$ years $/>12$ years).

Abbreviations: N, Number; PYs, person-years; IR, incidence rates; $95 \% \mathrm{Cl}, 95 \%$ confidence intervals; HR, hazard ratio.

$\mathrm{CI})=1.09(1.04-1.14)$ for women, and $1.37(1.20-1.56)$ for men in Gan et al's report versus $1.52(0.98-2.36)$ for women and 2.98 (1.58-5.62) for men in our study]. This was true even after adjustment for various confounding demographic, anthropometric, and biochemical parameters effects (age, gender, family history of diabetes, marital status and educational level, the baseline value of BMI, WC, hypertension, FPG, WBC, TG, HDL-C). However, as almost all of the working shifts with which our study was concerned were of the rotating-shift type, we were therefore unable to compare the magnitude of association among different types of shift work. Comparatively, these findings were contrary to those of a recent study by Silva-costa et $a{ }^{11}{ }^{11}$ based on the baseline data of the Brazilian Longitudinal Study of Adult Health (ELSABrazil), which reported that the association between night work and diabetes was stronger among women [OR (95\% $\mathrm{CI})=1.42(1.39-1.45)]$ than among men $[\mathrm{OR}(95 \% \mathrm{CI})$ 
Table 5 Distribution Of Physiological, Behavioral And Psychosocial Stress Among Shift Workers Group Separate By Gender

\begin{tabular}{|c|c|c|c|c|c|c|c|c|c|c|c|c|}
\hline \multirow[t]{3}{*}{ Parameter } & \multicolumn{6}{|c|}{ Female } & \multicolumn{6}{|c|}{ Male } \\
\hline & \multicolumn{2}{|c|}{$\begin{array}{l}\text { Day } \\
\text { Workers }\end{array}$} & \multicolumn{2}{|c|}{$\begin{array}{l}\text { Former } \\
\text { Shift Workers }\end{array}$} & \multicolumn{2}{|c|}{$\begin{array}{l}\text { Current } \\
\text { Shift Workers }\end{array}$} & \multicolumn{2}{|c|}{$\begin{array}{l}\text { Day } \\
\text { Workers }\end{array}$} & \multicolumn{2}{|c|}{$\begin{array}{l}\text { Former } \\
\text { Shift Workers }\end{array}$} & \multicolumn{2}{|c|}{$\begin{array}{l}\text { Current } \\
\text { Shift Workers }\end{array}$} \\
\hline & $\mathbf{N}$ & $\%$ & $\mathbf{N}$ & $\%$ & $\mathbf{N}$ & $\%$ & $\mathbf{N}$ & $\%$ & $\mathbf{N}$ & $\%$ & $\mathbf{N}$ & $\%$ \\
\hline \multicolumn{13}{|l|}{ Physiological stress } \\
\hline Hypertension incidence $(n=4740)$ & & & & & & & & & & & & \\
\hline $\begin{array}{l}\text { Yes } \\
\text { Overweight + obesity }(n=300 I)\end{array}$ & 297 & 11.9 & 41 & 10.6 & 101 & 10.4 & 130 & 18.4 & 16 & 21.6 & 29 & $27.9^{\mathrm{b}}$ \\
\hline $\mathrm{BMI} \geq 23 \mathrm{~kg} / \mathrm{m}^{2}$ & 341 & 20.7 & 59 & 20.9 & 134 & 21.6 & 95 & 26.5 & 9 & 22.5 & 20 & 36.4 \\
\hline Metabolic Syndrome incidence (MetS) & & & & & & & & & & & & \\
\hline MetS; WC $(n=4780)$ & 342 & 14.2 & 56 & 14.4 & $|3|$ & 14.8 & 160 & 20.5 & 13 & 15.9 & 26 & 26.5 \\
\hline MetS; BMI $\geq 23 \mathrm{~kg} / \mathrm{m}^{2}(\mathrm{n}=463 \mathrm{I})$ & 341 & 14.0 & 53 & 13.8 & 123 & 13.9 & 145 & 19.4 & 11 & 13.9 & 29 & $29.6^{b, c}$ \\
\hline \multicolumn{13}{|l|}{ Behavioral stress } \\
\hline \multicolumn{13}{|l|}{ Alcohol consumption $(n=5947)$} \\
\hline No & 2637 & 86.8 & 672 & 91.8 & 777 & $88.8^{\mathrm{a}}$ & 603 & 57.7 & 54 & 41.8 & 63 & $50.0^{\mathrm{a}}$ \\
\hline Former & $17 \mid$ & 5.6 & 22 & 3.0 & 45 & 5.1 & 104 & 10.0 & 17 & 13.2 & 12 & 9.5 \\
\hline Current & 232 & 7.6 & 38 & 5.2 & 53 & 6.1 & 338 & 32.3 & 58 & 45.0 & 51 & 40.5 \\
\hline \multicolumn{13}{|l|}{ Cigarette Smoking $(n=5947)$} \\
\hline No & 3007 & 98.9 & 728 & 99.5 & 869 & 99.3 & 873 & 83.5 & 92 & 71.3 & 95 & $75.4^{\mathrm{a}}$ \\
\hline Former & 23 & 0.8 & 4 & 0.5 & 2 & 0.2 & 78 & 7.5 & 20 & 15.5 & 15 & 11.9 \\
\hline Current & 10 & 0.3 & 0 & 0.0 & 4 & 0.5 & 94 & 9.0 & 17 & 13.2 & 16 & 12.7 \\
\hline \multicolumn{13}{|l|}{ Physical Exercise $(n=5947)$} \\
\hline Yes & 1384 & 45.5 & 341 & 46.6 & 381 & 43.5 & 692 & 66.2 & 85 & 65.9 & 63 & $50.0^{\mathrm{b}, \mathrm{c}}$ \\
\hline \multicolumn{13}{|l|}{ Meal frequency $(n=5947)$} \\
\hline 3 times/day & 2310 & 76.0 & 566 & 77.3 & 567 & $64.8^{b, c}$ & 798 & 76.4 & 96 & 74.4 & 98 & 77.8 \\
\hline I-2 times/day & 571 & 18.8 & 117 & 16.0 & 218 & 24.9 & 186 & 17.8 & 28 & 21.7 & 17 & 13.5 \\
\hline$>3$ times/day & 159 & 5.2 & 49 & 6.7 & 90 & 10.3 & 61 & 5.8 & 5 & 3.9 & II & 8.7 \\
\hline \multicolumn{13}{|l|}{ Fruit and Vegetable dietary intake $(n=5947)$} \\
\hline No or low & 472 & 15.5 & 96 & 13.1 & 133 & 15.2 & 187 & 17.9 & 21 & 16.3 & 29 & 23.0 \\
\hline Occasional consumption (I-3 days/week) & 1193 & 39.3 & 309 & 42.2 & 351 & 40.1 & 445 & 42.6 & 65 & 50.4 & 46 & 36.5 \\
\hline Everyday consumption (4-7 days/week) & 1375 & 45.2 & 327 & 44.7 & 391 & 44.7 & 413 & 39.5 & 43 & 33.3 & 51 & 40.5 \\
\hline \multicolumn{13}{|l|}{ Sleep duration (hours/night) $(n=5925)$} \\
\hline$<5$ hrs & 85 & 2.8 & 18 & 2.5 & 88 & $10.0^{b, c}$ & 32 & 3.1 & 5 & 3.9 & 12 & $9.6^{b}$ \\
\hline $5-6.9 \mathrm{hrs}$ & 1653 & 54.6 & 411 & 56.2 & 550 & 62.9 & 560 & 53.9 & 64 & 49.6 & 64 & 51.2 \\
\hline$\geq 7 \mathrm{hrs}$ & 1289 & 42.6 & 302 & 41.3 & 237 & 27.1 & 446 & 43.0 & 60 & 46.5 & 49 & 39.2 \\
\hline \multicolumn{13}{|l|}{ Sleep quality (Thai-PSQI) ( $n=5947)$} \\
\hline Good ( $\leq 5$ points) & 2053 & 67.5 & 487 & 66.5 & 483 & $55.2^{b, c}$ & 723 & 69.2 & 83 & 64.3 & 76 & $60.3^{\mathrm{b}}$ \\
\hline Poor (>5 points) & 987 & 32.5 & 245 & 33.5 & 392 & 44.8 & 322 & 30.8 & 46 & 35.7 & 50 & 39.7 \\
\hline \multicolumn{13}{|l|}{ Psychosocial stress } \\
\hline \multicolumn{13}{|l|}{ Working hours per day $(n=4019)$} \\
\hline $6-8 \mathrm{hrs}$ & 1855 & 62.1 & 384 & 54.1 & 423 & 48.7 & 653 & 63.3 & 80 & 63.0 & 69 & $54.8^{b, c}$ \\
\hline$>8-12 \mathrm{hrs}$ & 1022 & 34.2 & 282 & 39.8 & 220 & 25.4 & 335 & 32.4 & 43 & 33.9 & 26 & 20.6 \\
\hline$>12 \mathrm{hrs}$ & 110 & 3.7 & 43 & 6.1 & 225 & 25.9 & 44 & 4.3 & 4 & 3.1 & 31 & 24.6 \\
\hline \multicolumn{13}{|l|}{ Working hours per week $(n=4019)$} \\
\hline$\leq 48$ hrs week & 1972 & 66.0 & 404 & 57.0 & 428 & 49.3 & 691 & 67.0 & 86 & 67.7 & 66 & $52.4^{\mathrm{b}, \mathrm{c}}$ \\
\hline$>48 \mathrm{hrs} /$ week & 1015 & 34.0 & 305 & 43.0 & 440 & 50.7 & 341 & 33.0 & 41 & 32.3 & 60 & 47.6 \\
\hline
\end{tabular}

Notes: ${ }^{a}$ Significant difference between former shift workers and day workers at $\mathrm{p}$-value $<0.05$. ${ }^{\mathrm{b}}$ Significant difference between current shift workers and day workers at $\mathrm{p}$-value $<0.05$. ${ }^{\mathrm{C}}$ Significant difference between current shift workers and former shift workers at $\mathrm{p}$-value $<0.05$.

Abbreviations: N, Number; BMI, body mass index; WC, waist circumference; Thai-PSQI, the Thai version of the Pittsburgh Sleep Quality Index. 
$=1.06(1.04-1.08)]$. Due to differences in study design, it was difficult to compare the results of the ELSA-Brazil study with the results of the current study. Notably, the ELSA-Brazil study was a cross-sectional study, while the current research is a longitudinal study. Accordingly, further investigations are needed into the gender differential of such an association using a longitudinal research design comprising both men and women.

While our evidence of the gender differential regarding the association between shift work and diabetes contributes to research and findings in the field, our evidence that behavioral (physical exercise) and physiological (incidence of hypertension and MetS) consequences were the likely mediators of this differential proved to be a novel finding.

Since physical inactivity is a well-established risk factor of type 2 diabetes, ${ }^{30}$ a stronger association between shift-work exposure and reduced prevalence of physical exercise among men than women may partly explain the gender differential association of shift work and type 2 diabetes risk. Furthermore, men preferentially utilize carbohydrates as a fuel source when exercising; comparatively, women oxidize a greater proportion of lipids relative to carbohydrates when exercising. This means that a reduced physical activity level will affect the utilization of carbohydrate regarding women's metabolisms. This means that the detrimental impact for men will be greater than that of women in terms of diabetes risk. ${ }^{31}$ However, since the association between shift-work exposure and the prevalence of physical exercise is cross-sectional, future longitudinal studies are needed in order to verify this cause-effect association.

Similarly, there is a stronger association between shiftwork exposure and increased incidence of being overweight/obese (which is a strong and established type 2 diabetes risk factor) for men as compared with women. Hence, this contributes to a stronger magnitude regarding the relationship between shift work and type 2 diabetes. Furthermore, women tend to store more adipose tissue in subcutaneous areas, which compares to preferential visceral fat deposition in men. Since visceral fat deposition is generally related to increased insulin resistance and cardiometabolic risk, increased body weight, therefore, carries more adverse health impacts (including type 2 diabetes risk) for men as compared with women. ${ }^{31,32}$ This is supported by evidence showing that men are diagnosed as having diabetes with a BMI $1-3 \mathrm{~kg} / \mathrm{m}^{2}$ lower than that of women. $^{21}$
Additionally, stronger associations are demonstrated between shift-work exposure and increased incidence of established type 2 diabetes co-morbidities - such as hypertension and MetS - among men than among women. Since both of these conditions are supposed to be consequences of insulin resistance, this may imply that gender disparity regarding the association between shift work and later type 2 diabetes risk is also mediated via the insulin-resistance pathway.

Since data relating to the psychosocial consequences of shift work (such as work stress, work-life balance, and recovery from work) were not collected, we are unable to examine their potential role as mediators of the gender disparity regarding the association between shift work and future type 2 diabetes.

The strengths of this study include its longitudinal design, which used a relatively large study population incorporating a sufficient number of males and female workers. Moreover, our ascertainment of diabetes based on FPG level as well as other biochemical parameters is more valid than self-reported since they were measured in standardized manner at the University's biomedical laboratory. Finally, the potential confounding effect of many demographic, anthropometric, and biochemical parameters at baseline (such as age, gender, family history of diabetes, marital status and educational level, the baseline value of BMI, WC, hypertension, FPG, WBC, TG, HDL-C) were all considered in the statistical analysis.

However, this study also has several limitations. First, follow-up time was relatively short (the longest follow-up time was seven years), rendering a small number of new type 2 diabetes cases to limited statistical power in providing firm evidence for the difference of associations between shift-work exposure and type 2 diabetes risk between genders. We compensated this limitation by incorporating abnormal FPG. Second, most participants were healthcare workers, presumably with better-thanaverage health consciences, and so the generalizability of this study's findings to other occupations with different shift-work pattern may be limited. Third, shift-work exposure data were retrospectively collected using self-reported questionnaires, potentially leading to incomplete recall data and misclassifications of the exposure; however, this is part of the nature of a retrospective cohort study. Finally, this study was unable to control for the confounding effect of lifestyle factors (cigarette smoking, alcohol consumption, physical activity, and diet quality) in the multivariate modeling, nor was it able to verify whether gender 
discrepancy may be mediated via the differential effect shift work on these factors because data relating to these factors were obtained from recent questionnaire surveys, rather than at baseline and during the follow-up period. Furthermore, this limitation also hindered us in examining the joint effect of shift work and lifestyle factors on the increased type 2 diabetes and abnormal FPG risk, as suggested by recent evidence. ${ }^{33}$

\section{Conclusion}

This study suggests that shift work is a risk factor for abnormal FPG and type 2 diabetes and, furthermore, that this is a gender differential risk because the exposure and outcome association was more pronounced in men than in women. In addition, we also provide novel evidence that this gender differential might be mediated behaviorally (physical exercise) and psychologically (hypertension, and MetS incidence). The results suggest that preventive measures aiming at ameliorating shift work induced type 2 diabetes risk should pay more attention to men by targeting intervention measures pertaining to these potential mediators. Many potential mediators (such as work stress, work-life balance, recovery from work) are not sufficiently included in this investigation, accordingly, future longitudinal studies are needed for further examination into the possible role of this gender differential regarding the association between shift work and future type 2 diabetes.

\section{Acknowledgments}

This study was supported by The Ratchadapiseksompotch Fund, Faculty of Medicine, Chulalongkorn University (grant no. RA60/123), Thesis Grant for Doctoral Degree Student of the National Research Council of Thailand (NRCT), and the 100th Anniversary Chulalongkorn University Fund for Doctoral Scholarship. No sources of funding were involved in the paper's design, collection, analysis, interpretation, or report writing, nor did they affect the publication decision concerning this paper. The authors would like to thank the Thai Red Cross Society and Chulalongkorn University for their permission to use their health check-up databases this project. We would like to thank the Health Check-up Center of King Chulalongkorn Memorial Hospital and Faculty of Allied Health Sciences, Chulalongkorn University, for supporting these health check-up databases. Finally, we should like to thank all those who participated in this study.

\section{Author contributions}

All authors contributed towards data analysis, drafting and critically revising the paper, gave final approval of the version to be published, and agreed to be accountable for all aspects of the work.

\section{Disclosure}

The authors report no conflicts of interest in this work.

\section{References}

1. International Diabetes Federation. Diabetes Atlas 2015 7th ed. 2015. Available form: http://www.diabetesatlas.org/resources/previous-edi tions.html. Accessed May 8, 2019.

2. Cho NH, Shaw JE, Karuranga S, et al. IDF diabetes atlas: global estimates of diabetes prevalence for 2017 and projections for 2045. Diabetes Res Clin Pract. 2018;138:271-281. doi:10.1016/j.diabres.2018.02.023

3. Ogurtsova K, da Rocha Fernandes JD, Huang Y, et al. IDF diabetes atlas: global estimates for the prevalence of diabetes for 2015 and 2040. Diabetes Res Clin Pract. 2017;128:40-50. doi:10.1016/j. diabres.2017.03.024

4. International Diabetes Federation. Diabetes atlas 2000 1st ed. 2000. Available form: http://www.diabetesatlas.org/resources/previous-edi tions.html. Accessed May 8, 2019.

5. Axelsson J, Puttonen S. Night shift work increases the risk for type 2 diabetes. Evid Based Med. 2012;17(6):193-194. doi:10.1136/ebmed2012-100649

6. Wang XS, Armstrong ME, Cairns BJ, Key TJ, Travis RC. Shift work and chronic disease: the epidemiological evidence. Occup Med (Lond). 2011;61(2):78-89. doi:10.1093/occmed/kqr001

7. Knutsson A, Kempe A. Shift work and diabetes-a systematic review. Chronobiol Int. 2014;31(10):1146-1151. doi:10.3109/07420528.20 14.957308

8. Vimalananda VG, Palmer JR, Gerlovin H, et al. Night-shift work and incident diabetes among African-American women. Diabetologia. 2015;58(4):699-706. doi:10.1007/s00125-014-3480-9

9. Pan A, Schernhammer ES, Sun Q, Hu FB. Rotating night shift work and risk of type 2 diabetes: two prospective cohort studies in women. PLoS Med. 2011;8(12):e1001141. doi:10.1371/journal.pmed.1001141

10. Gan Y, Yang C, Tong X, et al. Shift work and diabetes mellitus: a meta-analysis of observational studies. Occup Environ Med. 2015;72 (1):72-78. doi:10.1136/oemed-2014-102150

11. Silva-Costa A, Rotenberg L, Nobre AA, Schmidt MI, Chor D, Griep RH. Gender-specific association between night-work exposure and type-2 diabetes: results from longitudinal study of adult health, ELSA-Brazil. Scand J Work Environ Health. 2015;41(6):569-578. doi:10.5271/sjweh. 3520

12. Ramin C, Devore EE, Wang W, Pierre-Paul J, Wegrzyn LR, Schernhammer ES. Night shift work at specific age ranges and chronic disease risk factors. Occup Environ Med. 2015;72(2):100107. doi:10.1136/oemed-2014-102292

13. Torquati L, Mielke GI, Brown WJ, Kolbe-Alexander T. Shift work and the risk of cardiovascular disease. A systematic review and metaanalysis including dose-response relationship. Scand J Work Environ Health. 2018;44(3):229-238. doi:10.5271/sjweh.3700

14. Eurofound. Sixth European Working Conditions Survey - Overview Report. Eurofound; 2015. Available form: https://www.eurofound. europa.eu/publications/report/2016/working-conditions/sixth-europeanworking-conditions-survey-overview-report. Accessed May 1, 2019.

15. IARC Working Group on the Evaluation of Carcinogenic Risks to Humans. Painting, firefighting, and shiftwork. IARC Monogr Eval Carcinog Risks Hum. 2010;98:9-764 
16. Alterman T, Luckhaupt SE, Dahlhamer JM, Ward BW, Calvert GM. Prevalence rates of work organization characteristics among workers in the U.S.: data from the 2010 National Health Interview Survey. Am J Ind Med. 2013;56(6):647-659. doi:10.1002/ajim.22108

17. Lee S, McCann D, Messenger JC. Working Time around the World: Trends in working hours, laws and policies in a global comparative perspective. Milton Park: Routledge; 2007.

18. Eriksson AK, van den Donk M, Hilding A, Östenson CG. Work stress, sense of coherence, and risk of type 2 diabetes in a prospective study of middle-aged Swedish men and women. Diabetes Care. 2013;36(9):2683-2689.

19. Puttonen S, Härmä M, Hublin C. Shift work and cardiovascular diseasepathways from circadian stress to morbidity. Scand $J$ Work Environ Health. 2010;36(2):96-108. doi:10.5271/sjweh.2894

20. Mauvais-Jarvis F. Sex differences in metabolic homeostasis, diabetes, and obesity. Biol Sex Differ. 2015;6:14. doi:10.1186/s13293-015-0033-y

21. Kautzky-Willer A, Harreiter J, Pacini G. Sex and gender differences in risk, pathophysiology and complications of type 2 diabetes mellitus. Endocr Rev. 2016;37(3):278-316. doi:10.1210/ er.2015-1137

22. American Diabetes Association. Diagnosis and classification of diabetes mellitus. Diabetes Care. 2010;33(Suppl 1):S62-69. doi:10.23 37/dc10-S062

23. WHO Expert Consultation. Appropriate body-mass index for Asian populations and its implications for policy and intervention strategies. Lancet. 2004;363:157-163. doi:10.1016/S0140-6736(03)15268-3

24. Anuurad E, Shiwaku K, Nogi A, et al. The new BMI criteria for Asians by the Regional Office for the Western Pacific Region of WHO are suitable for screening of overweight to prevent metabolic syndrome in elder Japanese workers. J Occup Health. 2003;45:335343. doi:10.1539/joh. 45.335
25. Alberti KG, Eckel RH, Grundy SM, et al. Harmonizing the metabolic syndrome: a joint interim statement of the international diabetes federation task force on epidemiology and prevention; National Heart, Lung, And Blood Institute; American Heart Association; World Heart Federation; International Atherosclerosis Society; and International Association for the Study of Obesity. Circulation. 2009;120(16):1640-1645. doi:10.1161/ CIRCULATIONAHA.109.192644

26. Sitasuwan T, Bussaratid S, Ruttanaumpawan P, Chotinaiwattarakul W. Reliability and Validity of the Thai Version of the Pittsburgh Sleep Quality Index. J Med Assoc Thai. 2014;97(Suppl.3):S57-S67.

27. Echouffo-Tcheugui JB, Dieffenbach SD, Kengne AP. Added value of novel circulating and genetic biomarkers in type 2 diabetes prediction: a systematic review. Diabetes Res Clin Pract. 2013;101(3):255269. doi:10.1016/j.diabres.2013.03.023

28. Collins GS, Mallett S, Omar O, Yu LM. Developing risk prediction models for type 2 diabetes a systematic review of methodology and reporting. BMC Med. 2011;9(103):103. doi:10.1186/1741-7015-9-103

29. Aday LA, Cornelius LJ. Preparing the data for analysis. In: Designing and Conducting Health Surveys: A Comprehensive Guide. 3rd ed. San Francisco: Jossey-Bass Inc.; 2006:350-359.

30. Hamasaki H. Daily physical activity and type 2 diabetes: a review. World J Diabetes. 2016;7(12):243-251. doi:10.4239/wjd.v7.i12.243

31. Varlamov O, Bethea CL, Roberts CT Jr. Sex-specific differences in lipid and glucose metabolism. Front Endocrinol (Lausanne). 2014;5:241.

32. Morikawa Y, Nakagawa H, Miura K, et al. Shift work and the risk of diabetes mellitus among Japanese male factory workers. Scand $J$ Work Environ Health. 2005;31(3):179-183. doi:10.5271/sjweh.867

33. Shan Z, Li Y, Zong G, et al. Rotating night shift work and adherence to unhealthy lifestyle in predicting risk of type 2 diabetes: results from two large US cohorts of female nurses. BMJ. 2018;363:k4641. doi:10.1136/bmj.k4029

\section{Publish your work in this journal}

Diabetes, Metabolic Syndrome and Obesity: Targets and Therapy is an international, peer-reviewed open-access journal committed to the rapid publication of the latest laboratory and clinical findings in the fields of diabetes, metabolic syndrome and obesity research. Original research, review, case reports, hypothesis formation, expert opinion and commentaries are all considered for publication. The manuscript management system is completely online and includes a very quick and fair peer-review system, which is all easy to use. Visit http://www.dovepress.com/testimonials.php to read real quotes from published authors.

Submit your manuscript here: https://www.dovepress.com/diabetes-metabolic-syndrome-and-obesity-targets-and-therapy-journal 